\title{
An animal model of the procognitive properties of cysteine protease inhibitor and immunomodulatory peptides based on colostrum
}

\author{
Bartłomiej Stańczykiewicz, ${ }^{1, A-D, F}$, Marta Jakubik-Witkowska ${ }^{1, B-D}$, Antoni Polanowski ${ }^{2, A, ~ D, ~ E, ~}$ \\ Tadeusz Trziszka ${ }^{2}, A, F$, Joanna Rymaszewska ${ }^{1}, A, E, F$ \\ ${ }^{1}$ Division of Consultation Psychiatry and Neuroscience, Department of Psychiatry, Wroclaw Medical University, Poland \\ ${ }^{2}$ Department of Animal Products Technology and Quality Management, University of Environmental and Life Sciences, Wrocław, Poland \\ A - research concept and design; B - collection and/or assembly of data; C - data analysis and interpretation; \\ $D$ - writing the article; $E$ - critical revision of the article; $F$ - final approval of article
}

Address for correspondence

Bartłomiej Stańczykiewicz

E-mail: bartlomiej.stanczykiewicz@umed.wroc.pl

Funding sources

None declared

Conflict of interest

None declared

\section{Acknowledgements}

The project was carried out within the framework of research aimed at promoting young scientists, funded by the Ministry of Science and Higher Education (registration number Pbmn 106).

Received on December 14, 2015

Revised on March 10, 2016

Accepted on April 06, 2016

\begin{abstract}
Background. The positive effect of human cystatin Con the development of Alzheimer's disease has been reported, as it inhibits the formation of $\beta$-amyloid oligomers and amyloidogenesis. Cystatin $C$ has been found to have a neuroprotective effect by inhibiting cysteine proteases, inducing autophagy and neurogenesis. There is a growing interest in the procognitive properties of colostrum-based specimens, which could delay dementia and ameliorate memory deterioration.
\end{abstract}

Objectives. The aim of the study was to evaluate the influence of ovocystatin and a Coloco peptide complex on the cognitive functions in reference to Colostrinin, using a model of young (4 month-old) and old (10-month-old) Wistar rats.

Material and methods. In the present study, the effects of ovocystatin [100 $\mu \mathrm{g} / \mathrm{rat}]$ and the Coloco peptide [ $4 \mathrm{\mu g} /$ /rat] $]$ derived from colostrum were assessed with respect to the reference specimen, Colostrinin [4 $\mu \mathrm{g} / \mathrm{rat}]$. The specimens were administered intraperitoneally and orally for 12 days. Cognitive functions were assessed using the Morris water maze (MWM).

Results. The group of young rats that received ovocystatin orally obtained significantly better results in the MWM compared to the placebo group $(p<0.05)$. Similarly, the group of young rats receiving Coloco orally obtained better results in the MWM compared to the placebo group and to the group of rats receiving Colostrinin $(p<0.05)$. There were no statistically significant differences in the oral and intraperitoneal administration of ovocystatin, Coloco and Colostrinin in the group of old rats.

Conclusions. The obtained results suggest that oral administration of ovocystatin and Coloco has beneficial effects on the cognitive functions of young rats.

Key words: ovocystatin, Coloco, Colostrinin (cln), Morris water maze, cognitive decline

DOI

$10.17219 /$ acem $/ 62536$

Copyright

Copyright by Author(s)

This is an article distributed under the terms of the

Creative Commons Attribution Non-Commercial License

(http://creativecommons.org/licenses/by-nc-nd/4.0/) 
Population aging results in an increased occurrence of cognitive impairment and dementia. There has been a recent growing interest in biologically active substances present in food such as proteins and peptides. Biologically active substances present in chicken eggs contain cysteine protease inhibitors, including egg white cystatinovocystatin. ${ }^{1}$ Ovocystatin, with a molecular weight of $13147 \mathrm{Da}$, is 44\% homologous in terms of the aminoacid sequence, $62-63 \%$ homologous in terms of the structural sequence and reveals similar biological functions as human cystatin C (Cys C) (molecular weight of 13 343-13 $359 \mathrm{Da}){ }^{2-4}$ As inhibitors of cysteine proteases, cystatins have the ability to inhibit enzymes such as papain or $\mathrm{B}, \mathrm{H}$, $\mathrm{L}$ and $\mathrm{S}$ cathepsins. An imbalance between proteases and their inhibitors may lead to the development of pathological conditions in humans. ${ }^{3,5}$

Numerous reports on Cys $\mathrm{C}$ suggest it has an important role in neurodegenerative diseases, such as Alzheimer's disease. Cys $C$ present in all tissues and body fluids has a wide range of biological properties, such as an antimicrobial and antiviral activity, a role in bone remodeling, neogenesis, modulation of the immune system, and the growth and proliferation of cells. ${ }^{6,7} \mathrm{Cys} \mathrm{C}$ co-deposits with amyloid- $\beta$ in the brains of people suffering from Alzheimer's disease and elderly people not diagnosed with dementia. Moreover, when Cys $C$ binds to $\beta$-amyloid, it inhibits its oligomerization and amyloidogenesis, and in doing so protects the brain from the toxic effects of $\beta$-amyloid. ${ }^{6-8}$ There have also been numerous reports concerning an association between a polymorphism in the Cys $C$ gene (CST3) and Alzheimer's disease. As association between the level of Cys $C$ in the blood and cerebrospinal fluid and cognitive impairment in the course of Alzheimer's disease has been found. The serum concentration of Cys C is low when Alzheimer's disease is asymptomatic, and decreases in the cerebrospinal fluid in patients with Alzheimer's disease. ${ }^{9,10}$ Additionally, attention is drawn to other protective mechanisms that Cys $\mathrm{C}$ has in neurodegenerative diseases, such as cysteine protease inhibition, inducing autophagy and neurogenesis. ${ }^{6,7}$ Therefore, ovocystatin may have an influence on cognitive functions.

There has also been a growing interest in the prolinerich polypeptide complex (PRP), discovered for the first time in ovine colostrums by Janusz et al. ${ }^{11}$ It has since been discovered that mammals other than sheep have analogues of colostral prolin-rich polypeptide (PRP) complex as a component of their colostrums. ${ }^{12}$ A PRP complex is an important immunomodulator that may induce maturation and differentiation murine thymocytes, promote peripheral blood leukocyte proliferation, induce various cytokines and is a potent antioxidant that significantly reduces 4-hydroxynonenal (4HNE)-mediated cellular damage in cell culture. ${ }^{11,13-15}$ Utilizing high-performance chromatography and mass spectroscopy, several dozen constituent peptides of colostral PRP later named Colostrinin $^{\circledast}$, have been identified. ${ }^{16}$ Subsequent studies showed that bovine colostrum may be considered as a suitable source for PRP production by means of methanol/ethanol extraction - Colostrinin or using aceton for fractionation. ${ }^{17,18}$ The later preparation has been named Coloco. The bovine preparations consist predominately of low molecular weight peptides of which both electrophoretic patterns and amino acid composition revealed a high degree of similarity to those of ovine Colostrinin ${ }^{\circledR}$. A typical for ovine Colostrinin ${ }^{\circledR}$ high level of prolin residues (about $20 \%$ ) and acidic amino acids (about 18\%) and low percentages of alanine, glycine, arginine, methionine and histidine, and an absence of tryptophane and cysteine residues was also found to be a characteristic feature for bovine preparations regardless of cow breeds. The employed methods of PRP separation and purification appeared to be reproducible and allow to obtain the PRP preparations very much similar to each other in terms of both chemical composition and biological activity.

The existing in vitro and in vivo studies suggest procognitive properties of Colostrinin. Popik et al. confirmed the positive effect of Colostrinin on cognitive functions in aged rats. ${ }^{19,20}$

Double-blinded studies carried out on patients with mild and moderate Alzheimer's disease showed that the oral administration of Colostrinin improves or stabilizes the state of the patient. ${ }^{21,22}$ Bilikiewicz et al. (2004) confirmed a positive effect of Colostrinin on cognitive functions as well as everyday functioning. ${ }^{23}$ In vitro studies showed that the nonapeptide fragment of the PRP complex (Val-Glu-Ser-Tyr-Val-Pro-Leu-Phe-Pro) may directly interact with $\beta$-amyloid and hence prevent the formation of toxic deposits. ${ }^{24}$ Here we present the first study analyzing the Coloco a peptide preparation, separated from cow colostrum according to the procedure described in the patent pending. ${ }^{18}$

The aim of the study was to assess the impact of ovocystatin (an analogue of the human cystatin C) and the Coloco peptide complex (obtained from colostrum) with reference to Colostrinin, on the cognitive functions of young and old rats.

\section{Material and methods}

\section{Study groups}

The study was carried out on male Wistar rats [young (4 month-old) and old (10-month-old)] at the Experimental Laboratory of the Department of Pathology at the Wroclaw Medical University. The rats were kept in cages of 2 in standard laboratory conditions, where the room temperature was around $22^{\circ} \mathrm{C}$ and there was a 12 -hour light cycle from 7:00 am to 7:00 pm. The animals were provided with food and water ad libitum.

The rats were assigned to study groups where drugs were administered either intraperitoneally (IP) or orally 
(O) at random. The specimens were administered in the following doses per animal: ovocystatin [100 $\mu \mathrm{g}]$, Coloco [4 $\mu \mathrm{g}$ ], Colostrinin (CLN) $[4 \mu \mathrm{g}]$ and the placebo $[0.9 \% \mathrm{NaCl}]$ at $0.5 \mathrm{~mL} / \mathrm{kg}$ over 12 days.

Groups consisted of 7 individuals apart from the subgroups of old rats receiving CLN orally and the placebo both orally and intraperitoneally. In these groups there were 6 rats.

The cognitive functions of the rats were assessed in the Morris water maze. The animals' body mass was assessed prior to and after the cognitive tests. Physical activity was measured before the rats were subjected to the Morris water maze test. All rats were transferred to the study room at least $60 \mathrm{~min}$ prior to commencing the test.

\section{Open field test - physical activity}

Physical activity was assessed in the open field test (distance, average speed of movement). The rats were placed in an open box individually and were observed for $10 \mathrm{~min}$. The box was cleaned using an alcohol-based agent after each rat.

\section{Morris water maze (MWM)}

Each rat was administered the specimen 30 min prior to undergoing the MWM test. The animal was then placed in a round water pool (182 cm wide, $30 \mathrm{~cm}$ deep) with a stable platform $10 \mathrm{~cm}$ wide, and the rat's head was directed to the wall of the pool. The pool water was at room temperature $\left(22^{\circ} \mathrm{C}\right)$ and was colored black with non-toxic paint to obtain a contrast between it and the white fur of the rat. Three days of adaptation and 9 days of acquisition training preceded the probe trial. The animals began each session during acquisition training from a different position $(\mathrm{N}, \mathrm{S}, \mathrm{W}, \mathrm{E})$. If the rat reached the platform before $120 \mathrm{~s}$, it remained on the platform for $5 \mathrm{~s}$ and then was removed from the pool. On the other hand, if the rat did not reach the platform, it was guided to it, and remained on it for $20 \mathrm{~s}$ before being taken out of the pool.

On day 13 (probe trial) the test was carried out without the platform. On day 14, (probe with a visible platform) the behavior of the rat when the position of the platform was changed (visible $1 \mathrm{~cm}$ above the water level) was tested. The measurement system that was applied included the Sony Color SSC-DC378P camera and a workstation, equipped with v. 2.5 of SMART software (PanLab, Spain).

\section{Reagents}

A proline-rich polypeptide complexes (PRP) Colostrinin and Coloco were isolated from bovine colostrum according to Kruzel et al. and Polanowski et al., respectively. ${ }^{17,18}$

Ovocystatin, monomeric form, was separated from chicken egg white as described in Gołąb et al. ${ }^{25}$

\section{Statistical analysis}

Data for the group of young and old rats was analyzed separately. In addition, control study subgroups were compared with each other. Ovocystatin was analyzed independently of Coloco and CLN. The oral and intraperitoneal routes of administration were also analyzed independently of one another. Parameters that changed with time (body weight, physical activity, Morris water maze parameters) were statistically analyzed using repeated measures ANOVA. An analysis of multiple repetitions was used as a post-hoc test with the Holm correction. On the day of running the Morris water maze test, the parameters were analyzed using classic ANOVA (1 or 2-way ANOVA). In two groups, depending on the results of the F test for the equality of variances, statistical analysis was carried out using the Student's t-test or the Welch test. The level of statistical significance was set at $\alpha=0.05$. Statistical analysis was carried out using v. 3.0.2 of the R statistical software for Windows (The R Foundation for Statistical Computing, Vienna, Austria), and v. 12.7.7 of MedCalc for Windows (MedCalc Software, Mariakerke, Belgium).

The study was carried out with the permission of the I Local Ethics Committee for Animal Experiments in Wrocław at the Institute of Immunology and Experimental Therapy of the Polish Academy of Sciences in Wrocław (permission no. 46/2012;74/2012;75/2012).

\section{Results}

\section{The effect of using the formulations on body mass}

The administration of ovocystatin intraperitoneally to young and old rats had no effect on their weight in the different subgroups compared to the placebo ( $p>0.05)$. However, the body mass of young rats increased with time ( $\mathrm{p}=0.001$ ), whereas the body mass of old rats decreased with time when ovocystatin was administered intraperitoneally ( $\mathrm{p}=0.007$ ). Administering ovocystatin orally to young and old rats did not affect their body mass. However, the body mass of animals in both age groups increased with time during the study period $(\mathrm{p}=0.002)$.

An intraperitoneal administration of Coloco and CLN did not affect weight in the subgroups of young and old rats. A significant association between body mass and group is associated with the loss of body mass of the old rats receiving the placebo $(\mathrm{p}=0.039)$. Administering the formulations orally had no effect on the body mass of young and old rats either. There was a significant interaction between time and the formulation used in the group of old rats receiving CLN, which was caused by a difference in body mass measurements in the first and second recordings (data not shown). 


\section{Assessing locomotor activity in the open field test}

The group of young rats assigned to the subgroup receiving ovocystatin intraperitoneally was significantly slower $(p=0.006)$ and covered a significantly shorter distance $(p=0.006)$ than animals in the placebo group. In the group of old rats, no differences in the average speed and distance travelled were noted.

The subgroup of young rats receiving ovocystatin orally was significantly slower $(\mathrm{p}=0.0017)$ and traveled a significantly shorter distance $(\mathrm{p}=0.0017)$ than animals in the placebo group, and old rats from the subgroup receiving ovocystatin orally were significantly faster $(\mathrm{p}=0.032)$ and moved a longer distance $(\mathrm{p}=0.03)$ than the placebo group.

The groups of young and old rats receiving Coloco and CLN orally did not differ in terms of their average speed and distance traveled $(\mathrm{p}>0.05)$. The group of young rats receiving Coloco in the form of an intraperitoneal injection was significantly slower and travelled a shorter distance than the group receiving CLN ( $p=0.0017$ ) or the placebo $(\mathrm{p}=0.0017)$. The group of old rats receiving

Fig. 1. Open Field Test - travelled distance

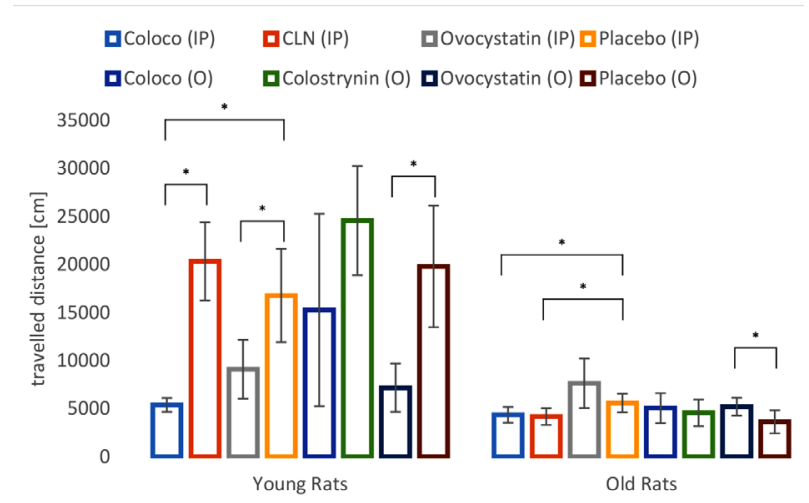

${ }^{*} \mathrm{p}<0.05$; IP - intraperitoneal administration; $\mathrm{O}$ - oral administration. Data are expressed as mean \pm SEM.

Fig. 2. Open Field Test - average speed

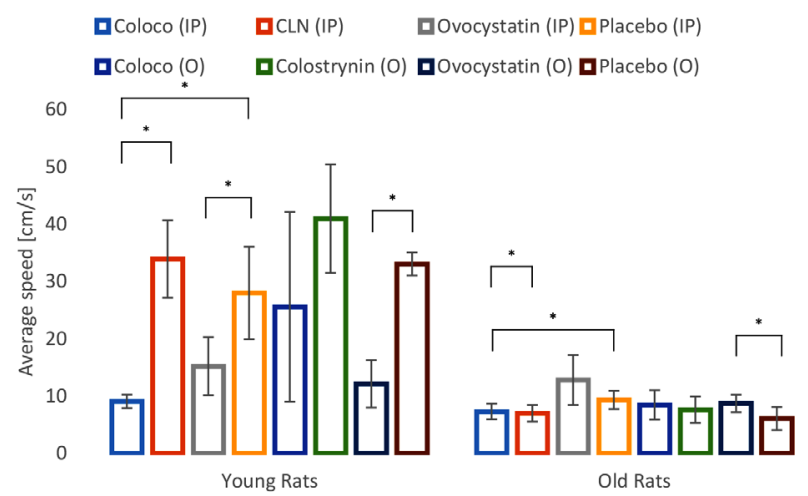

${ }^{*} \mathrm{p}<0.05$; IP - intraperitoneally administration; O - orally administration. Data are expressed as mean \pm SEM.
Coloco intraperitoneally had significantly higher average speed values than the CLN group $(\mathrm{p}=0.027)$ and lower than the placebo group ( $p=0.046$ ). The group of old rats from the placebo subgroup travelled a longer distance than those from the CLN ( $\mathrm{p}=0.027)$ and Coloco ( $\mathrm{p}=0.045)$ subgroups, where all the animals received the formulations intraperitoneally (Fig. 1-2).

\section{The effect of the formulations on cognitive function in the Morris water maze}

\section{Acquisition training}

In the group of young rats, intraperitoneal and oral administration of ovocystatin, Coloco and CLN did not shorten the time of the animals to find the platform, in comparison to the placebo group ( $p>0.05$ ). It was noticeable that the length of time it took the rats, both young and old, to find the platform decreased with each day of training $(\mathrm{p}<0.05)$. The group of young rats receiving Coloco intraperitoneally was significantly slower than the group receiving $C L N(p=0.022)$. However, these subgroups were not differ significantly from the control group. There were no differences between the remaining subgroups of young and old rats $(\mathrm{p}>0.05)$. Wishaw's error, which defines with what precision a given individual finds the hidden platform, did not show any significant differences in the subgroups of young and old rats receiving oral and intraperitoneal specimens. The parameter showed an upward trend over training time in all groups receiving specimens intraperitoneally and in the subgroup of young rats receiving ovocystatin intraperitoneally (data not shown).

\section{Probe trial}

There was a significant difference in the percentage of time spent in the target sector (PT\%) and the percentage of the distance covered in the target sector $(\mathrm{D} \%)$ between the group of young rats receiving ovocystatin orally and the

Fig. 3. Morris Water Maze - probe trial. Percentage of permanence time at target sector (PT\%) - IP administration

$$
\text { 口Coloco DColostrynin DOvocystatin 口Placebo }
$$

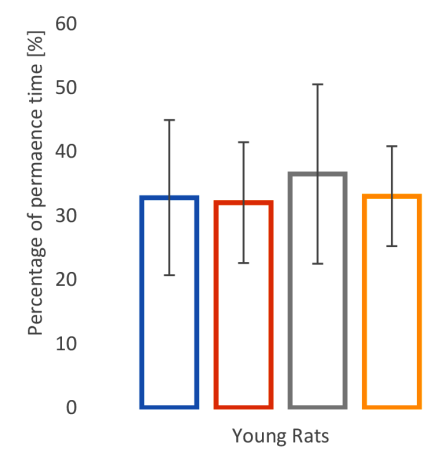

Data are expressed as mean \pm SEM.

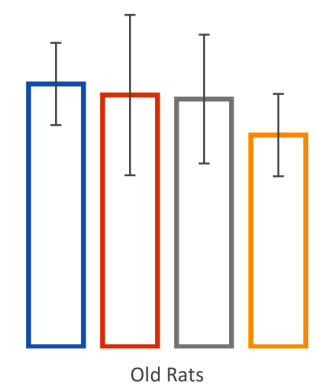

Old Rats 
Fig. 4. Morris Water Maze - Probe trial. Percentage of permanence time at target sector (PT\%) - Orally administration

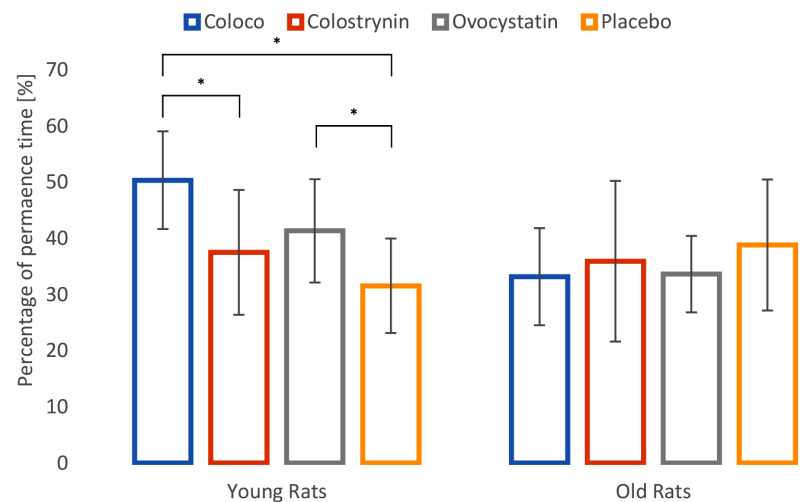

${ }^{*} p<0.05 ;$ Data are expressed as mean \pm SEM.

Fig. 5. Morris Water Maze - Probe trial. Percentage of permanence travelled distance at target sector (D\%) - IP administration

口Coloco DColostrynin DOvocystatin DPlacebo

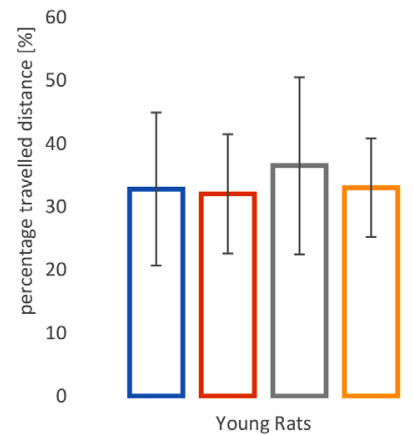

Data are expressed as mean \pm SEM.

Fig. 6. Morris Water Maze - Probe trial. Percentage of permanence travelled distance at target sector (D\%) - Orally administration

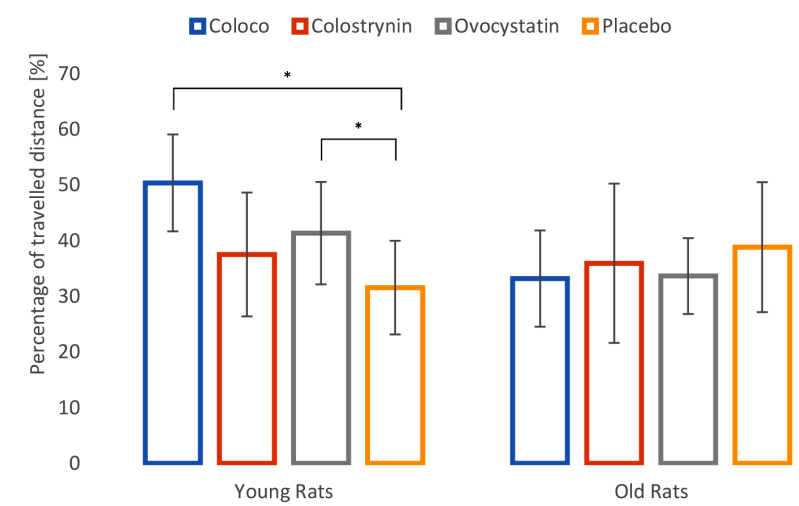

${ }^{*} \mathrm{p}<0.05$; Data are expressed as mean \pm SEM.

placebo group ( $\mathrm{p}=0.0027$ and $\mathrm{p}=0.010$ respectively). The group of young rats receiving Coloco orally differed significantly from both the placebo group ( $p=0.0048$ ) and the group receiving CLN ( $\mathrm{p}=0.0415)$ in terms of the percentage of time spent in the target sector (PT\%). A significant difference in the percentage of distance covered in the tar-
Fig. 7. Morris Water Maze - Probe with visible platform. Latency to find visible platform - IP administration

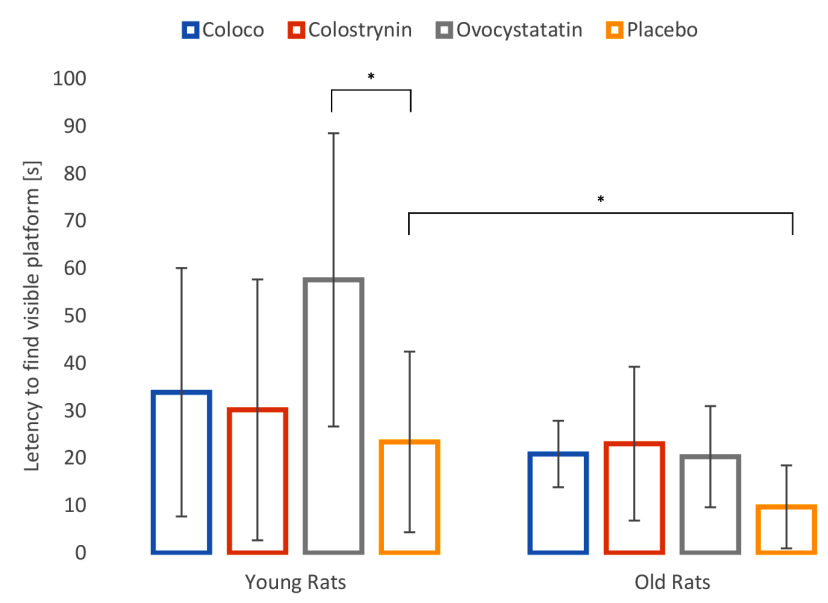

${ }^{*} p<0.05$; Data are expressed as mean \pm SEM.

Fig. 8. Morris Water Maze - Probe with visible platform. Latency to find visible platform - Orally administration

-Coloco aColostrynin a Ovocystatatin Dlacebo

60
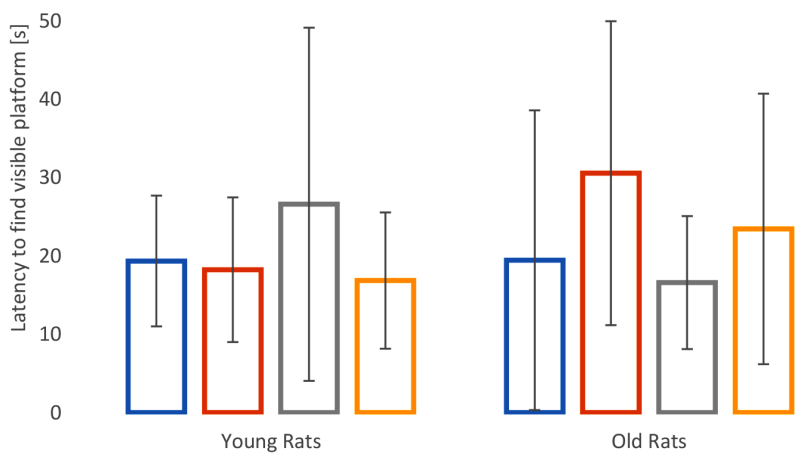

Data are expressed as mean \pm SEM.

get sector (D\%) in the subgroup of young rats receiving Coloco orally compared to the placebo $(\mathrm{p}=0.0037)$ was noted (Fig. 3-6).

\section{Probe with visible platform}

The subgroup of young rats receiving ovocystatin intraperitoneally took longer to find the platform when compared to the placebo group ( $p=0.042$ ). In the case of the old rats, there were no differences between the subgroups ( $p>0.05$ ) regarding the time needed to find the platform. Old rats found the platform faster than young rats in the subgroups of rats receiving the placebo $(p=0.025)$. No differences were found between the groups of young and old rats receiving ovocystatin orally ( $\mathrm{p}>0.05$ ) (Fig. 7-8).

No differences were found in the groups of young and old rats receiving Coloco, CLN and the placebo ( $\mathrm{p}>0.05)$. The subgroup of old rats receiving the placebo intraperitoneally found the platform faster than young rats 
$(\mathrm{p}=0.032)$. The oral administration of Coloco, CLN and the placebo did not lead to any significant changes in the measured parameters ( $p>0.05)$ (Fig. 7-8).

\section{Discussion}

The present results suggest ovocystatin obtained from chicken eggs and colostrum-based Coloco may have potential procognitive properties when given orally to the group of young rats. Unexpectedly, the administration of ovocystatine at a dose of $100 \mu \mathrm{g} / \mathrm{rat}$ and Coloco at $4 \mu \mathrm{g} / \mathrm{rat}$ resulted in an increased ability to concentrate in young individuals, even though it was speculated before carrying out the study that these specimens would have a positive effect on the cognitive functions of older individuals. The MWM and a modified scheme of this test, used in previous studies concerning CLN (a reference specimen in this study), were used to assess the procognitive properties of the studied specimens. ${ }^{19}$ The MWM allows the assessment of hippocampal-dependent spatial memory. The applied model of dementia allows the assessment of the activity of the studied specimens, and their influence on the deterioration, both natural and pathological, of an organism's cognitive functions. ${ }^{19,20}$ It also allows the identification of the influence of the specimens on the ability to concentrate in the case of young individuals. Although the results obtained in an animal model may not have direct implications in humans, it has been shown that the use of CLN in patients leads to cognitive improvements. ${ }^{21-23}$

It is also important to assess locomotor activity and exclude possible effects of the aging process on it, using the open field test. This test is also used in studies concerning anxiety. In the group of old rats, as opposed to the group of young rats, no differences were found, suggesting that the aging process did not affect locomotor activity. The observation of a certain locomotor activity in the group of young and old rats shows whether the animals have a sufficient physical condition to undergo further studies in the MWM. This study did not evaluate the effect of a given specimen supplementation on locomotor activity. However, in this study, the lack of a difference in the average swimming speed during the MWM workout between groups receiving the specimens and the placebo is consistent with earlier studies using CLN, and suggests a lack of effect of specimen supplementation on physical activity. ${ }^{13}$

Due to a significant structural similarity of ovocystatin - a chicken cystatin and human Cys $\mathrm{C}$, an attempt was made to determine the optimal route of administration of ovocystatin and its impact on the cognitive function. ${ }^{26}$ To date, the effect of direct administration of cystatin into the hippocampus was analyzed by Nagai et al. The study revealed a loss of neurons in the dentate gyrus in the brains of Sprague-Dawley rats, although an immu- nohistochemical analysis showed no $\beta$-amyloid formation. ${ }^{27}$ However, in vivo studies in the case of an overexpression of human Cys $\mathrm{C}$ in the brains of transgenic mice with a mutation in the amyloid precursor protein have shown that Cys $C$ inhibits the deposition of $\beta$-amyloid. It may also regulate processes of $\beta$-amyloidosis in thebrain, and may therefore have potential therapeutic use. ${ }^{28,29}$ In the present study, ovocystatin administered intraperitoneally was not found to have procognitive properties.

The results of the MWM carried out without a platform may be used as the basis for further studies regarding the procognitive effect of ovocystatin administered orally.

So far, the correlation of Cys $C$ with cognitive functions has been examined using the MWM, where the relationship of Cys C with cathepsin B with regard to the level of $\beta$-amyloid was studied in a mouse model of Alzheimer's disease. ${ }^{30}$ It is one of few studies analyzing Cys $\mathrm{C}$ and indicates its negative impact on the disease, which is contrary to the results of the present study.

In addition, the results obtained on the day when the platform was visible showed that young rats receiving ovocystatin intraperitoneally looked for the platform longer, especially when it was positioned in the opposite zone. This may mean that the animals remembered the previous location of the platform and spent more time trying to find it. A similar tendency, although not statistically significant, was seen in the group of young rats receiving ovocystatin orally.

World reports on the effects of the proline rich polypeptide complexes on cognitive functions indicate their procognitive properties both in humans and animals. ${ }^{19-23}$ The obtained results of the MWM without the platform suggest its effectiveness when given orally. Furthermore, no procognitive function was found in the group of old rats. The results of the group of young rats suggest that it may affect concentration.

The study has a number of limitations. One of these is a small study group. Also, the study was carried out using only 1 dose of each of the specimens. Possibly, increasing the range of dosages as well as the duration of use will contribute to achieving more promising results. Additionally, the study is limited to an animal model, which is subject to physiological aging and dementia. Therefore, it seems reasonable to continue the study using an animal model of Alzheimer's disease. Further studies concerning ovocystatin and Coloco in terms of cognitive disorders and neurodegenerative diseases are required. Taking into account a positive trend found in this study in the group of old rats (although not statistically significant), it seems necessary to continue the study using this age group.

In conclusion, the obtained results indicate procognitive properties of ovocystatin and Coloco and may contribute to further research concerning the impact of these specimens on cognitive functions and their mechanisms of action. 


\section{References:}

1. Sosnowska A, Trziszka T, Polanowski A, Bubel F. Bioactive substances of hen eggs. Their biomedical importance and technological possibility for production in an industrial scale. Przem Chem. 2011;90(5):174-179.

2. Rehault S. Antiproteases. In:. Huopalahti R, Lopez-Fandino R, Anton M, Schade R (eds.). Bioactive egg compounds. Berlin, Heidelberg: Springer Verlag. 2007:85-92.

3. Warwas M, Piwowar A. Urinary cystatin C as a biomarker of renal tubular injury. Postepy Hig Med Dosw. 2011;65:562-568.

4. Konopska B, Gburek J, Gołąb K, Warwas M. Influence of aminoglycoside antibiotics on chicken cystatin binding to renal brush-border membranes. J Pharm Pharmacol. 2013;65(7):988-994.

5. Gołąb K, Gburek J, Juszczyńska K, Trziszka T, Polanowski A. Stabilization of monomeric chicken egg white cystatin. Przem Chem. 2012;91(5):741-744.

6. Gauthier S, Kaur G, Mi W, Tizon B, Levy E. Protective mechanisms by cystatin $C$ in neurodegenerative diseases. Front Biosci (Schol Ed). 2011;3:541-554.

7. Kaur G, Levy E. Cystatin C in Alzheimer's disease. Front Mol Neurosci. 2012;5:79.

8. Levy E. Cystatin C. A potential target for Alzheimer's treatment. Expert Rev Neurother. 2008;8(5):687-689.

9. Sundelöf J, Arnlöv J, Ingelsson E, et al. Serum cystatin C and the risk of Alzheimer disease in elderly men. Neurology. 2008;71(14):1072-1079.

10. Hansson SF, Andréasson U, Wall M, et al. Reduced levels of amyloidbeta-binding proteins in cerebrospinal fluid from Alzheimer's disease patients. J Alzheimers Dis. 2009;16(2):389-397.

11. Janusz M, Lisowski J, Franek F. Isolation and characterisation of a prolinerich polypeptide from ovine colostrum. FEBS Letters. 1974;49:276-279.

12. Sokołowska A, Bednarz R, Pacewicz M, Georgiades JA, Wilusz T, Polanowski A. Colostrum from different mammalian species-A rich source of CLN. International Dairy Journal. 2008;18:204-209.

13. Janusz M, Lisowski J. Proline - rich polypeptide (PRP) - an immunomodulatory peptide from ovine colostrum. Archivum Immunologiae et Therapiae Experimentalis. 1993;41;275-279.

14. Zabłocka A, Janusz M, Macała J, Lisowski J. A proline-rich polypeptide complex (PRP) isolated from ovine colostrums. Modulation of $\mathrm{H}_{2} \mathrm{O}_{2}$ and cytokine induction in human leukocytes. International Immunopharmacology. 2007;7:981-988.

15. Stewart MG. CLN: A naturally occurring compound derived from mammalian colostrum with efficacy in treatment of neurodegenerative diseases, including Alzheimer's. Expert Opin Pharmacother. 2008;9(14):2553-2559.
16. Georgiades JA, Polanowski A, Wilusz T, Kruzel ML. Purification of peptides from colostrm. 2007. Patent EP 1613648 B1.

17. Kruzel ML, Polanowski A, Wilusz $T$, et al. The alcohol - induced conformational changes in casein micelles: A new challenge for the purification of Colostrinin. The Protein Journal. 2004;23:127-133.

18. Polanowski A, Wilusz T, Dobrzyński W, Bodzicz S. Process for the preparation of peptide formulation. 2015. Patent PL nr 218693.

19. Popik P, Bobula B, Janusz M, Lisowski J, Vetulani J. CLN, a polypeptide isolated from early milk, facilitates learning and memory in rats. Pharmacol Biochem Behav. 1999;64(1):183-189.

20. Popik P. CLN and CLN-derived nonapeptide (colostral-val nonapeptide, CVNP) facilitate learning and memory in rats. Pol J Pharmacol. 2001;53(2):166-168.

21. Leszek J, Inglot AD, Janusz M, Lisowski J, Krukowska K, Georgiades JA. CLN: A proline-rich polypeptide (PRP) complex isolated from ovine colostrum for treatment of Alzheimer's disease. A doubleblind, placebo-controlled study. Arch Immunol Ther Exp (Warsz). 1999;47(6):377-385.

22. Leszek J, Inglot AD, Janusz $M$, et al. CLN proline-rich polypeptide complex from ovine colostrum--a long-term study of its efficacy in Alzheimer's disease. Med Sci Monit. 2002;8(10):PI93-P196.

23. Bilikiewicz A, Gaus W. CLN (a naturally occurring, proline-rich, polypeptide mixture) in the treatment of Alzheimer's disease. J Alzheimers Dis. 2004;6(1):17-26.

24. Janusz M, Woszczyna M, Lisowski M, et al. Ovine colostrum nonapeptide affects amyloid beta aggregation. FEBS Lett. 2009;583(1):190-196.

25. Gołąb K, Gburek J, Juszczyńska K, Trziszka T, Polanowski A. Stabilization of monomeric chicken egg white cystain. Przem Chem. 2012;91:741-744

26. Gołąb K, Horowski A, Warwas M. Chicken cystatin as a model protein in medical science. Farm Pol. 2008;64(17):759-769.

27. Nagai A, Ryu JK, Terashima M, et al. Neuronal cell death induced by cystatin $C$ in vivo and in cultured human CNS neurons is inhibited with cathepsin B. Brain Res. 2005;1066(1-2):120-128.

28. Kaeser SA, Herzig MC, Coomaraswamy J, et al. Cystatin C modulates cerebral beta-amyloidosis. Nat Genet. 2007;39(12):1437-1439.

29. Mi W, Pawlik M, Sastre M, et al. Cystatin C inhibits amyloid-beta deposition in Alzheimer's disease mouse models. Nat Genet. 2007;39(12):1440-1442.

30. Sun B, Zhou Y, Halabisky B, et al. Cystatin C-cathepsin B axis regulates amyloid beta levels and associated neuronal deficits in an animal model of Alzheimer's disease. Neuron. 2008;60(2): 247-257. 